\title{
Spinal accessory nerve to triceps muscle transfer using long autologous nerve grafts for recovery of elbow extension in traumatic brachial plexus injuries
}

\author{
Liselotte F. Bulstra, MSc, ${ }^{1,3}$ Nadia Rbia, MD, ${ }^{1,3}$ Michelle F. Kircher, RN, ${ }^{1}$ Robert J. Spinner, MD, ${ }^{2}$ \\ Allen T. Bishop, MD, ${ }^{1}$ and Alexander Y. Shin, MD1 \\ Departments of ${ }^{1}$ Orthopedic Surgery, Division of Hand Surgery, and ${ }^{2}$ Neurosurgery, Mayo Clinic, Rochester, Minnesota; and \\ ${ }^{3}$ Department of Plastic, Reconstructive and Hand Surgery, Erasmus Medical Center, Rotterdam, The Netherlands
}

\begin{abstract}
OBJECTIVE Reconstructive options for brachial plexus lesions continue to expand and improve. The purpose of this study was to evaluate the prevalence and quality of restored elbow extension in patients with brachial plexus injuries who underwent transfer of the spinal accessory nerve to the motor branch of the radial nerve to the long head of the triceps muscle with an intervening autologous nerve graft and to identify patient and injury factors that influence functional triceps outcome.
\end{abstract}

METHODS A total of 42 patients were included in this retrospective review. All patients underwent transfer of the spinal accessory nerve to the motor branch of the radial nerve to the long head of the triceps muscle as part of their reconstruction plan after brachial plexus injury. The primary outcome was elbow extension strength according to the modified Medical Research Council muscle grading scale, and signs of triceps muscle recovery were recorded using electromyography. RESULTS When evaluating the entire study population (follow-up range 12-45 months, mean 24.3 months), $52.4 \%$ of patients achieved meaningful recovery. More specifically, $45.2 \%$ reached Grade 0 or 1 recovery, $19.1 \%$ obtained Grade 2 , and $35.7 \%$ improved to Grade 3 or better. The presence of a vascular injury impaired functional outcome. In the subgroup with a minimum follow-up of 20 months $(n=26)$, meaningful recovery was obtained by $69.5 \%$. In this subgroup, $7.7 \%$ had no recovery (Grade 0), $19.2 \%$ had recovery to Grade 1, and $23.1 \%$ had recovery to Grade 2 . Grade 3 or better was reached by $50 \%$ of patients, of whom $34.5 \%$ obtained Grade 4 elbow extension.

CONCLUSIONS Transfer of the spinal accessory nerve to the radial nerve branch to the long head of the triceps muscle with an interposition nerve graft is an adequate option for restoration of elbow extension, despite the relatively long time required for reinnervation. The presence of vascular injury impairs functional recovery of the triceps muscle, and the use of shorter nerve grafts is recommended when and if possible.

https://thejns.org/doi/abs/10.3171/2017.6.JNS17290

KEY WORDS brachial plexus injury; triceps muscle; elbow extension; nerve transfer; spinal accessory nerve; peripheral nerve

$\mathrm{T}$ RAUMATIC brachial plexus injuries are devastating injuries, resulting in severely impaired or complete flail upper extremities. Elbow flexion is traditionally considered to be the most important function to restore and is always prioritized, followed by restoration of shoulder function. ${ }^{23}$ Over the past few decades, reconstruction options have expanded, and reconstruction of other upperlimb functions, such as grasp and elbow extension, are becoming more important. Elbow extension is critical for stabilization of the elbow without having to use the healthy opposite arm in order to achieve a stable grasp and for any activity that requires the arm to be lifted above the horizontal position..$^{4,7,8,13}$ Double and single free-functioning muscle transfers (FFMTs) have taken on an important role in the reconstruction of prehensile function in complete brachial plexus injury., When restoration of prehensile function is attempted with FFMTs, elbow extension is imperative to act as an agonist to the free functional muscle

ABBREVIATIONS BMI = body mass index; EMG = electromyography; FFMT = free-functioning muscle transfer; $M R C=$ Medical Research Council.

SUBMITTED February 9, 2017. ACCEPTED June 5, 2017.

INCLUDE WHEN CITING Published online December 8, 2017; DOI: 10.3171/2017.6.JNS17290. 
transfer, which crosses the anterior elbow joint. ${ }^{8}$ Previous studies have shown that patients who undergo a double FFMT for combined elbow flexion and finger flexion and extension need at least British Medical Research Council $(\mathrm{MRC})^{19}$ Grade 2 elbow extension power to sufficiently stabilize their elbow while attempting finger movement. ${ }^{5,8}$ Moreover, in cases of insufficient (Grade 0-2) recovery of elbow flexion with primary surgery, a sufficiently reinnervated triceps muscle (Grade 4 or better) could be transferred to the biceps tendon to provide elbow flexion function..$^{15}$

Successful use of the spinal accessory nerve transfer has been described for restoration of elbow flexion and shoulder function. ${ }^{2,9,20,24}$ However, existing reports on the use of the spinal accessory nerve for triceps reinnervation (with an interpositional graft) are not sufficient to draw any conclusions about the usefulness of this transfer for elbow extension. The purpose of this study was to evaluate prevalence and quality of restored elbow extension in patients with traumatic brachial plexus injury who underwent transfer of the spinal accessory nerve to the radial nerve branch to the long head of the triceps muscle and to identify patient and injury-related factors that might influence functional outcome.

\section{Methods \\ Patient Population}

After approval from the institutional review board was granted, all patients who underwent a spinal accessory nerve transfer for triceps reinnervation after traumatic brachial plexus injury between 2001 and 2015 were identified. Patients without signs of spontaneous recovery who were at least 15 years old and with a minimum of 12 months of follow-up after surgery composed the cohort of the study.

Demographic data (including age, sex, body mass index [BMI], comorbidities, and smoking status) and injuryrelated factors (including mechanism of injury, extent of injury, dominant side affected, interval between injury and surgery, type and length of the used nerve graft, concomitant injuries, and concomitant surgeries) were retrieved from the medical charts. CT myelography, intraoperative electrical stimulation (somatosensory and motor evoked potentials) and radiographs were used to determine the extent of the injury. Patients also underwent MR angiography to evaluate for associated vascular injuries.

\section{Outcome Measures}

All patients underwent clinical evaluation performed by the senior authors (A.Y.S., A.T.B., and R.J.S.) pre- and postoperatively. Elbow extension muscle strength was evaluated and agreed on by the senior authors using the modified British MRC grading system..$^{19}$ Furthermore, signs of triceps muscle reinnervation on electromyography (EMG) were recorded. For the EMG measurements, reinnervation success was defined as measurable voluntary motor unit potentials in the reinnervated long head of the triceps muscle.

For patients who underwent an FFMT for reconstruction of finger flexion or combined finger and elbow flexion as part of their reconstructive plan, an MRC grade of 2 or higher in the triceps muscle was considered sufficient to stabilize the elbow. ${ }^{8}$ Therefore, in these cases an MRC grade $\geq 2$ was considered as meaningful recovery. For all other cases an MRC grade of 3 or higher was considered as meaningful recovery.

\section{Surgical Technique}

All patients underwent a transfer of the ipsilateral spinal accessory nerve to the motor branch of the radial nerve to the long head of the triceps muscle in combination with various reconstructive interventions to reconstruct upper limb functions in addition to elbow extension. These other interventions included reconstruction of elbow flexion (e.g., transfer of intercostal nerves to the biceps motor branch, gracilis FFMT innervated by intercostal nerves), shoulder stabilization (e.g., reinnervation of suprascapular and/or axillary nerve with viable nerve roots when available or nerve transfers such as a [hemi]contralateral C-7), and prehensile function (e.g., tendon transfer of the gracilis FFMT to the finger flexors). In this cohort, the spinal accessory nerve was only used for triceps muscle reinnervation. While shoulder function is important, triceps muscle function in the setting of an FFMT for finger flexion is necessary to act as an agonist. In patients who underwent FFMT for finger flexion, triceps muscle function thus became a priority, and shoulder function was restored by tendon transfers or arthrodesis and was included in the reconstructive plan. Details on the FFMT procedure were previously reported..$^{3,17}$

Through a supraclavicular approach, the supraclavicular plexus was explored. The spinal accessory nerve was identified on the medial border of the trapezius muscle and traced distally. A handheld nerve stimulator was used to verify the contraction of the trapezius muscle. The first motor ramus was identified, and the spinal accessory nerve was divided distal to this branch.

A deltopectoral incision was used to explore the infraclavicular plexus and expose the radial nerve and the branches that innervated the long head of the triceps muscle. These were dissected, mobilized proximally, and divided. An autologous nerve graft was harvested. The source of nerve graft depended on the other reconstructions being performed and included sural nerves, ipsilateral denervated superficial branch of the radial nerve, medial antebrachial cutaneous nerve, and lateral antebrachial cutaneous nerve. The nerve ends were sutured with the aid of an operative microscope by using two or three 9-0 nylon sutures, the nerve coaptation was wrapped with a split collagen nerve conduit (NeuraGen tube, Integra LifeSciences), and glued using fibrin glue (Tisseel, Baxter Healthcare Corp.). The procedure is schematically depicted in Fig. 1.

\section{Statistical Analysis}

Continuous variables (e.g., age, follow-up) are described as the mean with standard deviation for parametric data and median and range for nonparametric data. Categorical data are described using frequencies, median, and range.

For comparisons between the groups with and without meaningful recovery, various tests were used, including the Student t-test or Mann-Whitney U-test for continuous 

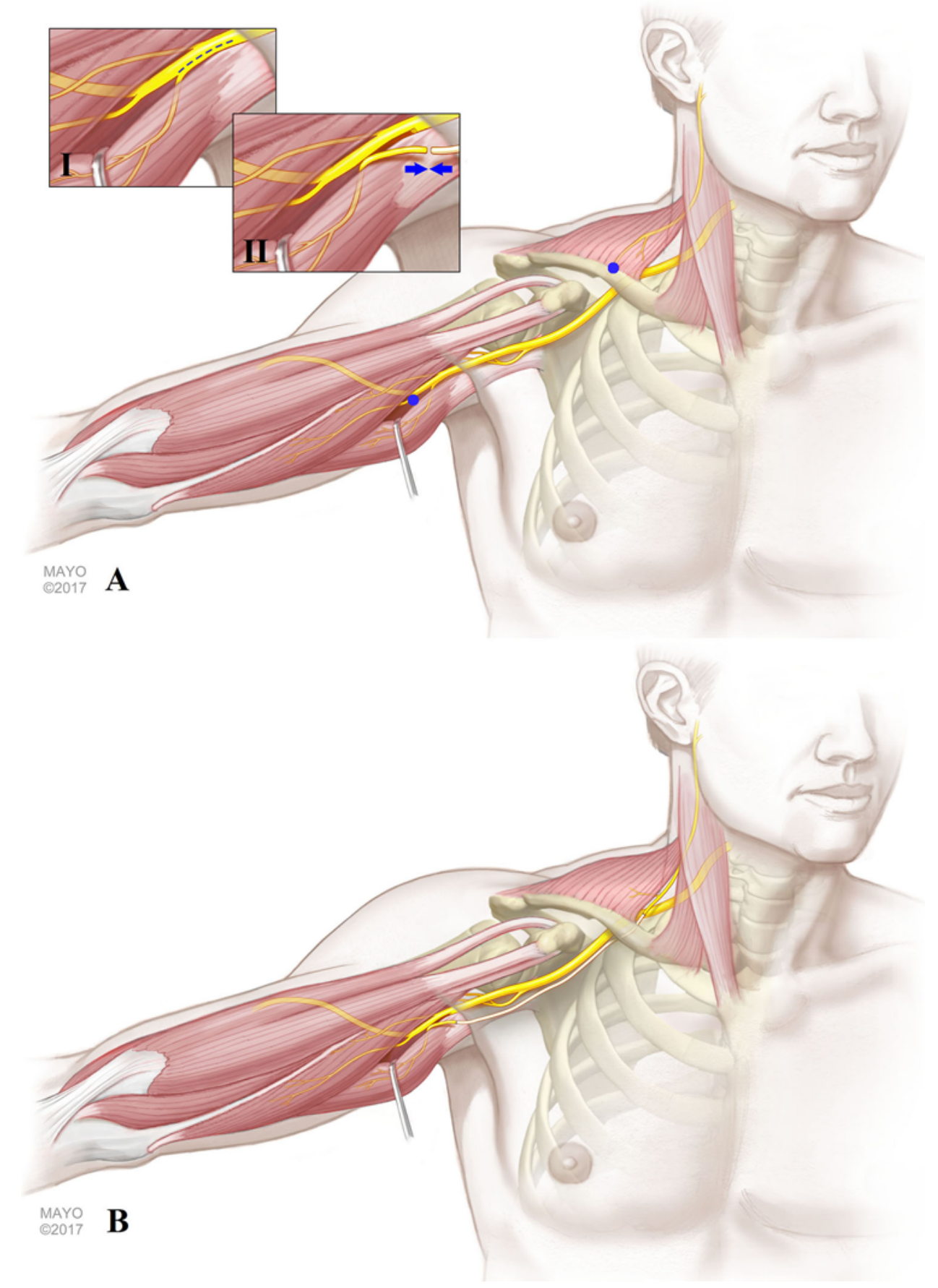

FIG. 1. Schematic overview of the transfer of the spinal accessory nerve to the radial nerve motor branch to the long head of the triceps muscle. A: The spinal accessory nerve is identified on the medial border of the trapezius muscle, traced distally, and divided distal to the first motor ramus (proximal blue dot). The radial nerve is exposed (distal blue dot), and its branches that innervate the long head of the triceps muscle are mobilized proximally and divided (inset I). The mobilized branch to the long head of the triceps muscle is connected to an autologous nerve graft (blue arrows, inset II). B: The nerve graft is proximally connected to the spinal accessory nerve, allowing for a tension-free coaptation. Used with permission of Mayo Foundation for Medical Education and Research. All rights reserved. Figure is available in color online only.

variables and chi-square or Fisher's exact test for categorical variables as appropriate. The Wilcoxon signed-rank test was used to compare pre- and postoperative MRC scores. Univariate logistic regression analysis was used to evaluate the effect of individual clinical and demographic factors. All statistical analyses were performed using SPSS Statistics (version 21, IBM Corp). Differences with $\mathrm{p}<0.05$ were considered statistically significant. 


\section{Results \\ Patient Demographics}

A total of 42 patients met the inclusion criteria. The demographic and clinical factors of these patients are outlined in Table 1. All patients had an absence of detectable triceps muscle function (Grade 0 ). The most common mechanism of injury was motorcycle accidents (42.9\%), followed by motor vehicle accidents $(21.9 \%)$, snowmobile accidents (11.9\%), bicycling injuries (4.8\%), and football accidents (4.8\%). Other mechanisms of injury (total $14.3 \%$ ) were all-terrain vehicle accidents, an earthquake, fall, snowboard injury, jet ski injury, and a pedestrian versus car accident ( $\mathrm{n}=1$ for each).

There were 7 patients (16.7\%) with incomplete injuries. These patients sustained the following injuries: C5-7 ( $\mathrm{n}=$ 2), C7-T1 ( $n=2)$, C6-8 $(n=1), C 5-8(n=1)$, and C6-T1 $(n=1)$. Sural nerve grafts were used in 10 patients. Within the group of patients who received an ipsilateral denervated donor nerve, the superficial branch of the radial nerve was used in 29 patients, the lateral antebrachial cutaneous nerve in 2 patients, and the medial antebrachial cutaneous nerve in 1 patient. Eight patients (19\%) had a BMI of $\geq 30 \mathrm{~kg} / \mathrm{m}^{2}$ and were categorized as obese. None of the patients had diabetes, and 5 patients $(11.9 \%)$ were reported as current smokers. No complications related to the spinal accessory nerve-triceps muscle transfer were reported, and all patients maintained upper trapezius muscle function (secondary to sparing of the first motor branch of the spinal accessory nerve). Regarding vascular injury, a dissection of the subclavian artery was found in 3 patients, stenosis of the axillary artery in 1 patient, and occlusion of the subclavian artery in 1 patient.

Thirty-one patients underwent an FFMT for finger flexion/prehension. The decision to perform an FFMT for prehension was made based on a combination of factors, including injury type, associated concomitant injuries, and patient preferences. The decision whether to use an FFMT was made a priori.

\section{Overall Results}

Meaningful recovery was reached by $52.4 \%$ of the 42 patients. The median follow-up of the overall cohort was 22.9 months (range 12.3-45.0 months). Meaningful recovery, as previously stated, was defined as a strength of Grade 2 or higher for FFMTs for prehension and Grade 3 or higher for triceps muscle function alone. The median postoperative MRC grade was 2 (range 0-4). Nine patients $(21.4 \%)$ regained no triceps muscle function (Grade 0$)$. Ten patients $(23.8 \%)$ regained Grade 1 triceps muscle strength, and Grade 2 was reached in 8 patients (19.1\%). MRC grades of 3 and 4 were reached in $6(14.3 \%)$ and $9(21.4 \%)$ patients, respectively. Elbow extension MRC grades were significantly improved after surgery $(p<0.001)$. Signs of recovery on EMG were detected in $47.6 \%$ of the patients. Meaningful recovery of triceps muscle function was not associated with demographic or clinical differences between groups, with the exception of follow-up time and the presence of vascular injury (Table 2).

To evaluate whether reconstruction of elbow extension
TABLE 1. Summary of patient demographics in 42 patients undergoing triceps muscle reinnervation

\begin{tabular}{lc}
\hline \multicolumn{1}{c}{ Variable } & Value \\
\hline Mean age at op \pm SD in yrs & $27.7 \pm 10.1$ \\
\hline Sex, $\mathrm{n}(\%)$ & $34(81)$ \\
\hline Male & $8(19)$ \\
\hline Female & $25.2(18.1-41.3)$ \\
\hline Median BMl in kg/m² (range) & $35(83.3)$ \\
\hline Extent of injury, $\mathrm{n}(\%)$ & $7(16.7)$ \\
\hline Complete & $20(47.6)$ \\
\hline Incomplete & $5.3(2.4-9.1)$ \\
\hline Dominant side affected, $\mathrm{n}(\%)$ & $10(23.8)$ \\
\hline Median time to op in mos (range) & $32(76.2)$ \\
\hline Nerve graft source, $\mathrm{n}(\%)$ & $15.0(10.0-25.0)$ \\
\hline Sural nerve & $31(73.8)$ \\
\hline Ipsilateral denervated nerve & $5(11.9)$ \\
\hline Median graft length in cm (range) & $5(11.9)$ \\
\hline FFMT for finger flexion, $\mathrm{n}(\%)$ & $22.9(12.3-45.0)$ \\
\hline Vascular injury, $\mathrm{n}(\%)$ &
\end{tabular}

is effective, we compared patients who received an FFMT for reconstruction of finger flexion or combined finger and elbow flexion with patients who did not receive an FFMT. Meaningful recovery ( $\geq$ Grade 2 ) was reached by $54.8 \%$ of the patients who received an FFMT $(n=31)$. For the patients who did not receive an FFMT $(n=11), 45.5 \%$ regained meaningful recovery ( $\geq$ Grade 3 ). The difference between these groups was not statistically significant $(\mathrm{p}=$ $0.59)$ with regard to triceps muscle function.

\section{Subgroup Analysis of Patients With At Least 20 Months of Follow-Up}

The follow-up time was significantly different between the groups with and without meaningful recovery $(p=0.003$, Table 2$)$. A subgroup analysis was conducted among patients with a minimum of 20 months of followup $(n=26)$. In this subgroup analysis, follow-up time was no longer significantly different between the groups with and without meaningful recovery (Table 3). Within this subgroup, 4 patients $(15.4 \%)$ sustained incomplete brachial plexus injury, of whom 2 patients had a C5-7 level injury and 2 patients a C7-T1 level injury. Nine patients $(34.6 \%)$ received a sural nerve graft. Of the other 17 patients (65.4\%), a superficial branch of the radial nerve graft was used in 16 patients, and a medial antebrachial cutaneous nerve graft was used in 1 patient.

The median MRC score was 2.5 (range 0-4). Two patients $(7.7 \%)$ did not regain any triceps muscle function. Five patients $(19.2 \%)$ reached Grade 1, and 6 patients (23.1\%) had Grade 2 function. Fifty percent of this subgroup reached Group 3 or better, with $34.5 \%$ achieving Grade 4. We found that after a mean follow-up of 30 months (range 20.85-44.89 months) meaningful recov- 
TABLE 2. Comparison between patients with and without meaningful recovery

\begin{tabular}{lccl}
\hline \multicolumn{1}{c}{ Variable } & $\begin{array}{c}\text { Meaningful } \\
\text { Recovery }(\mathrm{n}=22)\end{array}$ & $\begin{array}{c}\text { No Meaningful } \\
\text { Recovery }(\mathrm{n}=20)\end{array}$ & $\begin{array}{c}\mathrm{p} \\
\text { Value }\end{array}$ \\
\hline Age in yrs & $27.8 \pm 11.39$ & $27.6 \pm 8.87$ & 0.67 \\
\hline Time to op in mos & $5.2 \pm 1.44$ & $5.2 \pm 1.56$ & 0.95 \\
\hline Follow-up in mos & $28.4 \pm 9.1$ & $19.7 \pm 7.57$ & $0.003^{*}$ \\
\hline Graft length in cm & $15.8 \pm 3.59$ & $17.1 \pm 4.26$ & 0.35 \\
\hline BMl in kg/m ${ }^{2}$ & $26.8 \pm 6.14$ & $25.8 \pm 4.6$ & 0.69 \\
\hline Male sex, $\mathrm{n}(\%)$ & $18(81.8)$ & $16(80)$ & 1 \\
\hline Complete injury, $\mathrm{n}(\%)$ & $17(77.3)$ & $18(90)$ & 0.41 \\
\hline Sural nerve graft, $\mathrm{n}(\%)$ & $6(27.3)$ & $4(20)$ & 0.72 \\
\hline Dominant side, $\mathrm{n}(\%)$ & $9(40.9)$ & $11(55)$ & 0.36 \\
\hline Smoking, $\mathrm{n}(\%)$ & $3(13.6)$ & $2(10)$ & 1 \\
\hline Vascular injury, $\mathrm{n}(\%)$ & $0(0)$ & $5(25)$ & $0.018^{*}$ \\
\hline
\end{tabular}

Data are presented as the mean $\pm \mathrm{SD}$, unless otherwise noted.

* Statistically significant $(p<0.05)$.

ery was obtained by $69.5 \%$, and $57.7 \%$ of patients showed signs of reinnervation on EMG.

Meaningful recovery of triceps muscle function was not associated with demographic or clinical differences between the groups (Table 3). The influence of vascular injury and smoking could not be evaluated in this subgroup due to the small number of cases ( 3 patients were reported smokers and only 1 patient had sustained vascular injury).

Meaningful recovery was reached by $73.7 \%$ of the 19 patients who received an FFMT for elbow and/or finger flexion. Of the patients who did not receive an FFMT (n $=7$ ), $57.1 \%$ regained meaningful recovery. The difference between these groups was not statistically significant ( $\mathrm{p}$ $=0.64$ ).

To further evaluate the influence of clinically important factors, we performed a univariate logistic regression analysis within this subgroup (Table 4). Although not reaching significance $(\mathrm{p}=0.058)$, functional recovery seems to be impaired when longer grafts are used (OR $0.785,95 \%$ CI $0.611-1.008$ ). Age, time to surgery, graft length, and BMI were not found to significantly influence functional outcome.

\section{Discussion}

Patients with partial or complete loss of their upper-extremity function due to brachial plexus injury are severely disabled. Traditionally, reconstruction of elbow flexion and shoulder function are considered the main priorities in brachial plexus reconstruction..$^{12,23}$ More recently, reconstructive goals have expanded, including reconstruction of elbow extension. Especially when reconstruction of prehensile function is aimed for or in cases of brachial plexus injury in which hand function is spared, reconstruction of elbow extension is imperative for obtaining meaningful use of the hand and should be considered a priority. ${ }^{4,8}$ This study aimed to evaluate the prevalence and quality of restored elbow extension in patients with traumatic bra-
TABLE 3. Comparison of recovery outcomes in the 26 patients with at least 20 months of follow-up

\begin{tabular}{lccc}
\hline \multicolumn{1}{c}{ Variable } & $\begin{array}{c}\text { Meaningful } \\
\text { Recovery }(\mathrm{n}=18)\end{array}$ & $\begin{array}{c}\text { No Meaningful } \\
\text { Recovery }(\mathrm{n}=8)\end{array}$ & $\begin{array}{c}\mathrm{p} \\
\text { Value }\end{array}$ \\
\hline Age in yrs & $29.7 \pm 11.7$ & $27.5 \pm 9.8$ & 0.644 \\
\hline Time to op in mos & $5.3 \pm 1.49$ & $5.1 \pm 1.59$ & 0.849 \\
\hline Follow-up in mos & $31.1 \pm 7.6$ & $27.1 \pm 6.5$ & 0.338 \\
\hline Graft length in cm & $15.6 \pm 3.67$ & $19.4 \pm 4.5$ & 0.103 \\
\hline BMl in $\mathrm{kg} / \mathrm{m}^{2}$ & $27.05 \pm 6.3$ & $26.3 \pm 2.9$ & 0.932 \\
\hline Male sex, $\mathrm{n}(\%)$ & $14(77.8)$ & $6(75)$ & 1 \\
\hline Complete injury, $\mathrm{n}(\%)$ & $15(83.3)$ & $7(87.5)$ & 1 \\
\hline Sural nerve graft, $\mathrm{n}(\%)$ & $6(33.3)$ & $3(37.5)$ & 1 \\
\hline Dominant side, $\mathrm{n}(\%)$ & $7(38.9)$ & $3(37.5)$ & 1 \\
\hline
\end{tabular}

Data are presented as the mean $\pm \mathrm{SD}$, unless otherwise noted.

chial plexus injury who underwent transfer of the spinal accessory nerve to the radial nerve branch to the long head of the triceps muscle and to identify patient and injuryrelated factors that may influence functional outcome.

Dodakundi et al. ${ }^{5}$ and Doi et $a .^{8}$ found that triceps muscle strength of at least Grade 2 provided sufficient power to achieve a stable elbow while attempting finger movement in patients who received a double FFMT for combined elbow flexion and finger flexion and extension. Thus, we classified triceps function of at least Grade 2 as meaningful recovery in patients who also underwent FFMT for finger and elbow flexion (31 of 42) and at least Grade 3 for patients without this FFMT.

In our cohort of 42 patients, $52.4 \%$ obtained meaningful recovery. The percentage of meaningful recovery was not statistically significantly different $(\mathrm{p}=0.59)$ when we compared patients with and without an FFMT; thus, the nerve transfer performed in this study (spinal accessory nerve-to-branch to the long head of the triceps muscle) seems to be equally useful in both groups.

Although the minimum follow-up for inclusion was 12 months, a number of patients may not have reached maximum clinical recovery at the time of their last follow-up. Given the fact that follow-up time was significantly different between the groups with and without meaningful recovery, 12 months may be too short for patients who undergo this specific transfer to reach their final recovery. To minimize the influence of patients who had not reached their final outcome, we performed a subgroup analysis of

TABLE 4. Univariate logistic regression analysis in the subgroup with at least 20 months of follow-up

\begin{tabular}{lccc}
\hline Variable & OR & $95 \% \mathrm{Cl}$ & $\mathrm{p} \mathrm{Value}$ \\
\hline Age & 1.02 & $0.942-1.104$ & 0.630 \\
\hline Time to op & 1.056 & $0.594-1.876$ & 0.853 \\
\hline Follow-up & 1.089 & $0.954-1.244$ & 0.207 \\
\hline Graft length & 0.785 & $0.611-1.008$ & 0.058 \\
\hline BMl & 1.028 & $0.871-1.214$ & 0.741 \\
\hline
\end{tabular}


patients with a minimum of 20 months of follow-up (Table 3). After a mean follow-up of 30 months (range 20.8544.89 months), the percentage of patients who reached meaningful recovery was considerably higher at $69.5 \%$.

\section{Association of Long Nerve Grafts and Longer Time to Reinnervation}

Although the influence of an increase in graft length did not reach the arbitrary significance level $(p=0.058)$, possibly due to the sample size, the OR of 0.785 (95\% CI 0.611-1.008) does indicate an important effect. In line with our findings and current concepts in literature, it is advisable to use shorter grafts when and if possible. ${ }^{26}$ This is supported by the findings of Baltzer et al. ${ }^{2}$ who reported an average of 10 months before EMG evidence of infraspinatus reinnervation was detected after spinal accessory nerve-to-infraspinatus muscle transfer without the use of an interposition graft. Thus, the knowledge that this transfer requires a relatively long time before functional recovery is to be expected must be relayed to patients.

With the growing interest in restoration of elbow extension in total or partial brachial plexus injury, several other surgical techniques have been proposed. Articles specifically reporting triceps muscle recovery after reinnervation with the intercostal transfer demonstrate widely varying results, with a reported recovery of Grade 3 or better varying from $0 \%$ to $90 \%$. All studies have a long follow-up of at least 24 months. ${ }^{6,11,14,18,30}$ The worst recovery (all $\leq$ Grade 2) was reported by Zheng et al. ${ }^{30}$ who combined an intercostal nerve transfer for elbow extension with a phrenic nerve transfer for elbow flexion. When we compare our group of patients who had an FFMT and a minimum of 20 months of follow-up with the study of Doi et al. ${ }^{6}$ consisting of 25 patients who underwent the double free-muscle technique with a minimum of 24 months of follow-up, the percentage of Grade 2 or better recovery is similar $(68 \%$ for Doi et al. ${ }^{6}$ vs $73.7 \%$ in our cohort). However the percentage of patients attaining Grade 3 or better triceps muscle function is higher in our cohort (50\%) than that of $28 \%$ in the study of Doi et al. ${ }^{6}$ Furthermore, the intercostal nerve is typically used for reconstruction of elbow flexion at our institution. ${ }^{23}$ Yang et al. ${ }^{28}$ conducted a review on a contralateral C-7 transfer for the treatment of traumatic brachial plexus injury and concluded that outcomes of contralateral C-7 transfer for triceps muscle recovery vary strongly, with an average of 50\% elbow extension recovery of Grade 3 or better. Besides the unpredictable results, lack of independent function and donor site morbidity to the uninjured contralateral extremity are important disadvantages of this technique..$^{29}$

We recognize the limitations that are inherent to a retrospective study with a relatively small cohort of patients. Due to its subjective nature, the modified MRC scale for grading manual muscle strength is controversial. In future studies, it is therefore advised that more objective measurement techniques are used. ${ }^{22}$ The discrepancy in the percentage of recovery measured by means of manual strength testing and EMG may be due to the fact that the exact location of the needles for the EMG was not always reported. It is possible that in some cases, parts other than the long head of the triceps muscle were measured, giving a falsenegative result.
Ideally, a larger cohort of patients would be studied to identify factors predictive of functional outcome, allowing for more advanced multivariable regression analysis. In our series, we found that the presence of vascular injury seems to impair the chance of reaching meaningful recovery. Contrary to other studies, we did not find a significant effect of BMI or smoking on the functional recovery in this study. ${ }^{16}$ This can probably be explained by the distribution and the small number of patients who smoked $(\mathrm{n}=$ 5 ) or were obese $(n=8)$, causing a lack of power to detect any effects.

Furthermore, there are presumably factors that influence results that were not evaluated in this study. A potentially important factor is the amount of physical therapy patients received. As antagonistic functions (elbow flexion and extension) are reconstructed using several nerve and muscle transfers, this requires complicated motor relearning and cortical reorganization. Unfortunately, we were not able to adequately evaluate this in this retrospective study, but it should be addressed in future research.

Reinnervation of the radial nerve branch to the long head of the triceps muscle has shown favorable results in comparison with targeting the radial nerve. ${ }^{10}$ The ratio between myelinated fibers in the donor spinal accessory nerve (> 800 at the terminal end) and myelinated fibers in the receiving radial nerve branch to the long head of the triceps $(\sim 1200)$ is believed to be sufficient. ${ }^{21,26,27}$ However, due to variations in the radial nerve anatomy, it is never certain how many axons will actually reach the target organ, and in some less likely cases, another nerve branch of the radial nerve might have been targeted. ${ }^{25}$

\section{Conclusions}

Especially in cases of brachial plexus injury in which prehensile function is restored or preserved, reinnervation of the triceps muscle is recommended. In our series, we found that transfer of the spinal accessory nerve to the radial nerve branch to the long head of the triceps is an adequate option for restoration of elbow extension, despite the relatively long time required for reinnervation. The presence of vascular injury impairs functional recovery of the triceps muscle, and the use of shorter nerve grafts is recommended when possible.

\section{References}

1. Adams JE, Kircher MF, Spinner RJ, Torchia ME, Bishop AT, Shin AY: Complications and outcomes of functional free gracilis transfer in brachial plexus palsy. Acta Orthop Belg 75:8-13, 2009

2. Baltzer HL, Wagner ER, Kircher MF, Spinner RJ, Bishop AT, Shin AY: Evaluation of infraspinatus reinnervation and function following spinal accessory nerve to suprascapular nerve transfer in adult traumatic brachial plexus injuries. Microsurgery 37:365-370, 2017

3. Barrie KA, Steinmann SP, Shin AY, Spinner RJ, Bishop AT: Gracilis free muscle transfer for restoration of function after complete brachial plexus avulsion. Neurosurg Focus 16(5):E8, 2004

4. Bertelli JA: Lower trapezius muscle transfer for reconstruction of elbow extension in brachial plexus injuries. J Hand Surg Eur Vol 34:459-464, 2009

5. Dodakundi C, Doi K, Hattori Y, Sakamoto S, Fujihara Y, 
Takagi T, et al: Outcome of surgical reconstruction after traumatic total brachial plexus palsy. J Bone Joint Surg Am 95:1505-1512, 2013

6. Doi K, Muramatsu K, Hattori Y, Otsuka K, Tan SH, Nanda V, et al: Restoration of prehension with the double free muscle technique following complete avulsion of the brachial plexus. Indications and long-term results. J Bone Joint Surg Am 82:652-666, 2000

7. Doi K, Sakai K, Kuwata N, Ihara K, Kawai S: Double freemuscle transfer to restore prehension following complete brachial plexus avulsion. J Hand Surg Am 20:408-414, 1995

8. Doi K, Shigetomi M, Kaneko K, Soo-Heong T, Hiura Y, Hattori Y, et al: Significance of elbow extension in reconstruction of prehension with reinnervated free-muscle transfer following complete brachial plexus avulsion. Plast Reconstr Surg 100:364-374, 1997

9. Emamhadi M, Alijani B, Andalib S: Long-term clinical outcomes of spinal accessory nerve transfer to the suprascapular nerve in patients with brachial plexus palsy. Acta Neurochir (Wien) 158:1801-1806, 2016

10. Flores LP, Socolovsky M: Phrenic nerve transfer for reconstruction of elbow extension in severe brachial plexus injuries. J Reconstr Microsurg 32:546-550, 2016

11. Gao K, Lao J, Zhao X, Gu Y: Outcome after transfer of intercostal nerves to the nerve of triceps long head in 25 adult patients with total brachial plexus root avulsion injury. $\mathbf{J}$ Neurosurg 118:606-610, 2013

12. Giuffre JL, Kakar S, Bishop AT, Spinner RJ, Shin AY: Current concepts of the treatment of adult brachial plexus injuries. J Hand Surg Am 35:678-688, 2010 (Erratum in J Hand Surg Am 35:1226, 2010)

13. Goubier JN, Teboul F: Transfer of the intercostal nerves to the nerve of the long head of the triceps to recover elbow extension in brachial plexus palsy. Tech Hand Up Extrem Surg 11:139-141, 2007

14. Goubier JN, Teboul F, Khalifa H: Reanimation of elbow extension with intercostal nerves transfers in total brachial plexus palsies. Microsurgery 31:7-11, 2011

15. Hoang PH, Mills C, Burke FD: Triceps to biceps transfer for established brachial plexus palsy. J Bone Joint Surg Br 71:268-271, 1989

16. Lee JY, Kircher MF, Spinner RJ, Bishop AT, Shin AY: Factors affecting outcome of triceps motor branch transfer for isolated axillary nerve injury. J Hand Surg Am 37:23502356, 2012

17. Maldonado AA, Kircher MF, Spinner RJ, Bishop AT, Shin AY: Free functioning gracilis muscle transfer with and without simultaneous intercostal nerve transfer to musculocutaneous nerve for restoration of elbow flexion after traumatic adult brachial pan-plexus injury. J Hand Surg Am 42:293. e1-293.e7, 2017

18. Malungpaishrope K, Leechavengvongs S, Witoonchart K, Uerpairojkit C, Boonyalapa A, Janesaksrisakul D: Simultaneous intercostal nerve transfers to deltoid and triceps muscle through the posterior approach. J Hand Surg Am 37:677682,2012

19. Mendell JR, Florence J: Manual muscle testing. Muscle Nerve 13 Suppl:S16-S20, 1990

20. Merrell GA, Barrie KA, Katz DL, Wolfe SW: Results of nerve transfer techniques for restoration of shoulder and elbow function in the context of a meta-analysis of the English literature. J Hand Surg Am 26:303-314, 2001

21. Schreiber JJ, Byun DJ, Khair MM, Rosenblatt L, Lee SK, Wolfe SW: Optimal axon counts for brachial plexus nerve transfers to restore elbow flexion. Plast Reconstr Surg 135:135e-141e, 2015

22. Shahgholi L, Bengtson KA, Bishop AT, Shin AY, Spinner RJ, Basford JR, et al: A comparison of manual and quantitative elbow strength testing. Am J Phys Med Rehabil 91:856862,2012

23. Shin AY, Spinner RJ, Steinmann SP, Bishop AT: Adult traumatic brachial plexus injuries. J Am Acad Orthop Surg 13:382-396, 2005

24. Songcharoen P, Mahaisavariya B, Chotigavanich C: Spinal accessory neurotization for restoration of elbow flexion in avulsion injuries of the brachial plexus. J Hand Surg Am 21:387-390, 1996

25. Uerpairojkit C, Ketwongwiriya S, Leechavengvongs S, Malungpaishrope K, Witoonchart K, Mekrungcharas N, et al: Surgical anatomy of the radial nerve branches to triceps muscle. Clin Anat 26:386-391, 2013

26. Vathana T, Larsen M, de Ruiter GC, Bishop AT, Spinner RJ, Shin AY: An anatomic study of the spinal accessory nerve: extended harvest permits direct nerve transfer to distal plexus targets. Clin Anat 20:899-904, 2007

27. Witoonchart K, Leechavengvongs S, Uerpairojkit C, Thuvasethakul $\mathrm{P}$, Wongnopsuwan V: Nerve transfer to deltoid muscle using the nerve to the long head of the triceps, part I: an anatomic feasibility study. J Hand Surg Am 28:628-632, 2003

28. Yang G, Chang KW, Chung KC: A systematic review of contralateral C7 transfer for the treatment of traumatic brachial plexus injury: part 1. Overall outcomes. Plast Reconstr Surg 136:794-809, 2015

29. Yang G, Chang KW, Chung KC: A systematic review of outcomes of contralateral C7 transfer for the treatment of traumatic brachial plexus injury: part 2. Donor-site morbidity. Plast Reconstr Surg 136:480e-489e, 2015

30. Zheng MX, Xu WD, Qiu YQ, Xu JG, Gu YD: Phrenic nerve transfer for elbow flexion and intercostal nerve transfer for elbow extension. J Hand Surg Am 35:1304-1309, 2010

\section{Disclosures}

The authors report no conflict of interest concerning the materials or methods used in this study or the findings specified in this paper.

\section{Author Contributions}

Acquisition of data: Shin, Bulstra, Kircher, Spinner, Bishop. Analysis and interpretation of data: Bulstra, Rbia. Drafting the article: Bulstra. Critically revising the article: Shin. Reviewed submitted version of manuscript: Shin, Rbia. Approved the final version of the manuscript on behalf of all authors: Shin. Statistical analysis: Bulstra. Administrative/technical/material support: Kircher. Study supervision: Shin, Spinner, Bishop.

\section{Supplemental Information}

\section{Previous Presentations}

Portions of this work were presented at the biannual meeting of the Dutch Society for Plastic Surgery (NVPC), Rotterdam, The Netherlands, October 8, 2016.

\section{Correspondence}

Alexander Y. Shin, Hand Surgery, Mayo Clinic, 200 First St. SW, Rochester, MN 55901. email: shin.alexander@mayo.edu. 